\title{
Association of a Novel Pinus monticola Chitinase Gene (PmCh4B) with Quantitative Resistance to Cronartium ribicola
}

\author{
Jun-Jun Liu, Richard A. Sniezko, and Abul K. M. Ekramoddoullah
}

First and third authors: Pacific Forestry Centre, Canadian Forest Service, Natural Resources Canada, 506 West Burnside Road, Victoria, BC, V8Z 1M5, Canada; and second author: United States Department of Agriculture Forest Service, Dorena Genetic Resource Center, 34963 Shoreview Road, Cottage Grove, OR 97424.

Accepted for publication 28 March 2011.

\begin{abstract}
Liu, J.-J., Sniezko, R. A., and Ekramoddoullah, A. K. M. 2011. Association of a novel Pinus monticola chitinase gene $(P m C h 4 B)$ with quantitative resistance to Cronartium ribicola. Phytopathology 101:904911.

Multiple families of pathogenesis-related (PR) proteins are believed to contribute to plant quantitative resistance to various pathogens. Along with other host PR proteins, PR3 chitinase is one protein component participating in genetic resistance of western white pine (Pinus monticola) to the white pine blister rust (WPBR) pathogen (Cronartium ribicola). In the present study, we characterized a novel $P$. monticola class IV chitinase gene $(\mathrm{PmCh} 4 \mathrm{~B})$ and further analyzed its nucleotide variations in the open-pollinated seed families of diverse geographical distribution and variable levels of quantitative resistance to C. ribicola

infection. PmCh4B showed high haplotype diversity $(H d=0.94)$ and nucleotide diversity $(\pi=0.00965)$, similar to those of other conifer genes related to environmental stresses. A low level of intragenic linkage disequilibrium (LD) (but most of the levels with statistical significance) was found within a distance of $\approx 800 \mathrm{bp}$. Based on $P m C h 4 B$ haplotype frequency, moderate to high levels of population structure were observed among $P$. monticola seed families currently used in breeding programs for WPBR resistance (average $F_{S T}=0.163, P<0.001$ ). Association analysis revealed that allelic variants and multiple single-nucleotide polymorphisms of $P m C h 4 B$ were significantly associated with quantitative levels of $P$. monticola resistance against $C$. ribicola. This work represents the first association study for quantitative resistance in western white pine pathosystem and provides a potential for marker-assisted selection in white pine breeding.
\end{abstract}

Forest conifer trees generally contain at most intermediate levels of both genetic and phenotypic variation due to long life spans with large natural out-crossing populations (35). Most economically and ecologically important characteristics of forest trees are quantitative traits with continuous variations resulting from interactions of genetic and environmental factors. Linkage disequilibrium (LD)-based association mapping does not require specially designed crosses between inbred parents and can be applied to collections of genotypes with unknown genetic relationships. Therefore, it is very useful as an alternative to traditional linkage-based methods for the identification of quantitative trait loci (QTL) by associated DNA markers in plants. By resequencing positional or functional candidate genes and performing sequence analysis of single-nucleotide polymorphism (SNP) data, the candidate gene-based association approach is an effective strategy to determine genetic effects of alleles (haplotypes) on complex phenotypes $(8,29)$. To reveal the genetic variation of potential candidate genes is a key step for marker-trait associations, which would lead to marker-assisted selection applicable in genomics-based breeding and plant health diagnostics (29). This is particularly useful in forest trees because pedigree-based mapping populations cannot be easily generated (38).

The ultimate objective of candidate gene-based association mapping is to identify functional genetic variants that are responsible for phenotypic variation. How to obtain large numbers

Corresponding author: J.-J. Liu; E-mail address: Jun-Jun.Liu@ NRCan-RNCan.gc.ca

* The $\boldsymbol{e}$-Xtra logo stands for "electronic extra" and indicates that Figure 3 appears in color online.

doi:10.1094/PHYTO-10-10-0282

C 2011 Her Majesty the Queen in right of Canada, Natural Resources Canada, Canadian Forest Service of genotypes of functional genes from individuals of many families or large populations is still a challenge in forest conifers. SNPs provide the richest gene variation, with great potential for the detection of genotype-phenotype associations (33). Thus far, genetic variations at the nucleotide level have only been investigated for a few conifer genes $(12,13,16,42)$, with special interest in association study of wood property traits (14).

Western white pine (Pinus monticola, Dougl. Ex D. Don) is a valuable, fast-growing tree of interest in the western United States and British Columbia (BC), Canada for forest plantations and sustainable forest ecosystems. This conifer also exhibits excellent genetic resistance to root rot caused by Onnia tomentosus, Armillaria spp., or Phellinus spp., with wide distribution in western North America. However, since it was introduced in the early 1900s, the invasive pathogen white pine blister rust (WPBR, Cronartium ribicola) has caused severe reductions in populations of $P$. monticola and other native five-needle pines in the United States and Canada. Breeding programs in the past few decades have found that $P$. monticola possesses both qualitative and quantitative resistance mechanisms against $C$. ribicola (19). Knowledge about molecular mechanisms underlying genetic resistance to WPBR is very limited in western white pine and related conifers $(16,26)$. SNP characterization has provided potential functional markers to tag candidate genes related to disease resistance in angiosperms. Candidate gene markers based on resistance- or defense-related genes provide useful tools for molecular characterization of host resistance in crops and model plants $(24,34)$. Therefore, investigation of genetic variations of host defenserelated genes would provide necessary information for identifying QTL involved in complex traits of partial resistance in conifer pathosystems.

In the present study, we selected chitinase genes as candidate genes contributing to partial resistance to $C$. ribicola in western 
white pine because such plant enzymes are likely involved in the host defense response by upregulation under attack by various pathogens and pests (25). Plant chitinases are divided into several classes (I to VII) because they show a wide diversity in protein structures, enzymatic properties, and subcellular localizations (31). Because their gene expression is induced following infection, plant chitinases are also considered to be pathogenesis-related (PR) proteins and classified into four PR families (PR3, PR4, PR8, and PR11) (31). The important role that chitinases play in the plant-defense system has been evidenced by in vitro antifungal activity of purified plant chitinases as well as enhanced resistance against fungal infections in transgenic plants overexpressing related genes (31). One $26-\mathrm{kDa}$ isozyme of the $P$. monticola class IV chitinase (PmCh4) family was discovered to exclusively accumulate in partially resistant (slow canker growth [SCG]) seedlings but not in susceptible seedlings following fungal challenge (25), suggesting that PmCh4 is one of the defense components against $C$. ribicola infection.

The objective of this work was to characterize nucleotide variations of the PmCh4 gene in western white pine. Nucleotide polymorphisms of one novel $P$. monticola class IV chitinase gene $(P m C h 4 B)$ and its SNP association with quantitative resistance are described here for the first time for this conifer species. Experimental exploration of marker-trait association will shed new light on fundamental research questions important for planning future studies on genetic variation at the genome scale in larger numbers of seed families of this species from throughout western North America.

\section{MATERIALS AND METHODS}

Plant materials. Twenty open-pollinated seed families of $P$. monticola collected in breeding programs with a wide geographical distribution were used in the present study. Each seed family represented a wild collection because the pollen cloud was from local geographic areas to the parent (Fig. 1). Among four BC-originated seed families (numbers 1 to 4), BL3110 was tested with quantitative stem resistance phenotypes described as SCG (15) while Wh3115 was shown to be a susceptible family (25). The other two BC seed families (WK3671 and WK3674) were selected in breeding program but the resistance levels of their progenies were not available. Sixteen U.S.-originated seed families were collected from the Colville (number 5), Mt. BakerSnoqualmie (numbers 6 to 10), Gifford Pinchot (numbers 11 to 17) (Washington), and the Mt. Hood National Forests (Oregon) (numbers 18 to 20). Fifteen of them showed variable phenotypes of quantitative stem resistance described as bark reaction (BR) $(36,37)$. The family BS81-003 (number 7) displayed phenotypes termed as resistance mechanism " $\mathrm{X}$ " (36) and its progeny showed resistance levels ranging from complete susceptibility (rust dead) to complete stem resistance (stem symptom-free), including BR, delayed stem infection, fewer stem infections, and longer time to mortality compared with susceptible controls. These 20 seed families represent a sample of genetic resources with partial resistance against white pine blister rust in North America. In total, 290 trees from the 20 seed families were sampled and analyzed in this study.

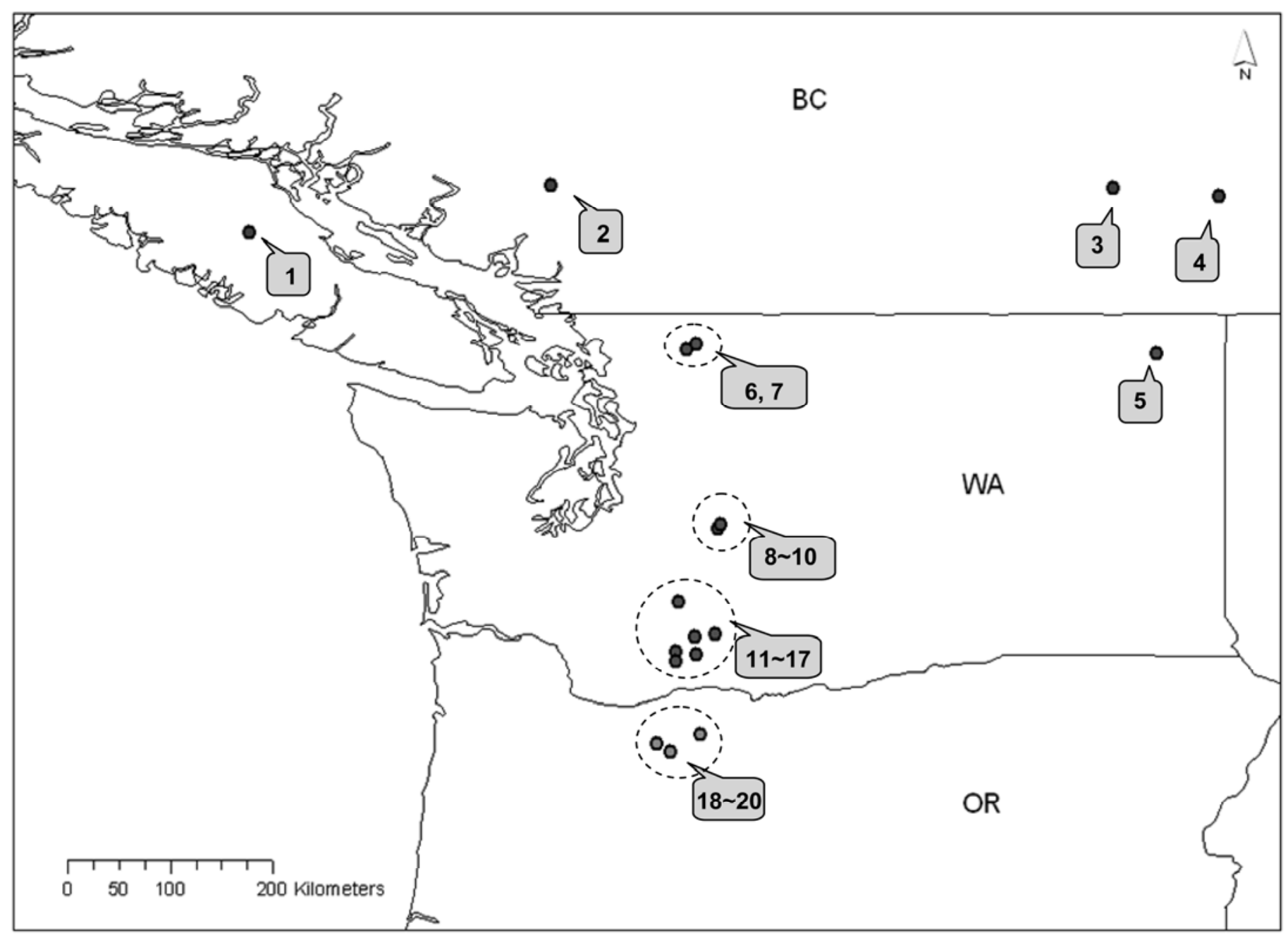

Fig. 1. Sites in western North America where 20 western white pine seed families were collected. Seed families corresponding to the numbers (1 to 7) are shown in Table 2. 
White pine seedling inoculation and phenotypic measurement of quantitative resistance. Seed of 16 U.S.-originated families (numbers 5 to 20) were sowed in 2003 and the seedlings were inoculated artificially by basidiospores of $C$. ribicola in fall 2004 at the United States Department of Agriculture Forest Service, Dorena Genetic Resource Center (Cottage Grove, OR). Disease symptoms were assessed on a yearly basis for the next 5 years using a series of parameters, including presence or absence of aecia, canker damage and severity, and number of stem symptoms by type, such as normal canker, partial BR (with incomplete inhibition of fungal growth), complete BR (without fungal activity in bark), or "clean" or stem-symptom free $(36,37)$. Partial resistance levels (Table 1) were quantitatively ranked for resistance phenotypes from level 0 (rust dead) to level 10 (stem symptom-free) for each seedling of 18 seed families (numbers 1 to 2 and numbers 5 to 20 ).

DNA extraction, polymerase chain reaction cloning, and sequencing. Needle samples were collected individually from each seedling. Genomic DNA was extracted using a Qiagen DNeasy kit (Qiagen Inc., Mississauga, ON, Canada). Of 20 seed families, 7 of them (numbers 1 to 7 ) with a total of 115 trees (Table 2) were used for SNP discovery in western white pine chitinase genes. Genomic DNA fragments were amplified by polymerase chain reaction (PCR) using a pair of primers $\mathrm{CH} 5$ (5'CAG AGT TTC TTC AAT GG-3') and CH3 (5'-ATT CTT CAT CCA GAA CCA-3'), which targeted two conserved motifs (QSFFNG and WFWMKN) of the plant class IV chitinase family. PCR was performed using a PCR Master Mix Kit (Qiagen Inc.) in a final volume of $25 \mu \mathrm{l}$, containing 5 to $10 \mathrm{ng}$ of genomic DNA on a Perkin-Elmer Themocycler (Perkin-Elmer Applied Biosystems, Foster City, CA). Thermal cycling conditions were set up as an initial template denaturation step at $94^{\circ} \mathrm{C}$ for $3 \mathrm{~min}$; followed by 35 cycles of denaturation at $94^{\circ} \mathrm{C}$ for $40 \mathrm{~s}$, primer annealing at $45^{\circ} \mathrm{C}$ for $1 \mathrm{~min}$, and primer extension at $72^{\circ} \mathrm{C}$ for $1.5 \mathrm{~min}$; with a final 10 -min extension at $72^{\circ} \mathrm{C}$.

The PCR fragments were resolved by $1 \%$ agarose gel electrophoresis. The DNA bands with expected sizes ( 0.7 to $0.9 \mathrm{~kb})$ were

TABLE 1. Phenotypic ranking of stem partial resistance

\begin{tabular}{lclc}
\hline Res/Sus & \multicolumn{1}{c}{ Phenotype $^{\mathrm{c}}$} & Tree $(n)^{\mathrm{d}}$ \\
\hline Sus & 0 & Rust dead & 33 \\
Sus & 1 & NC + aecia & 47 \\
Sus & 3 & NC only; no aecia & 10 \\
Sus & 4 & NC and PBR; no aecia & 17 \\
Sus & 5 & NC, BR, and PBR; no aecia & 5 \\
Res & 6 & PBR only; no aecia & 71 \\
Res & 7 & PBR and BR; no aecia & 14 \\
Res & 8 & BR only; no aecia & 20 \\
Res & 10 & SS-free (clean) & 48 \\
\hline
\end{tabular}

a Res $=$ resistant and Sus = susceptible.

${ }^{b}$ Resistance levels were based on the assessment in the third year postinoculation.

c BR, bark reaction; NC, normal canker growth; PBR, partial bark reaction; SS, stem symptom.

${ }^{\mathrm{d}}$ In total, 265 trees were collected from 18 seed families (numbers 1 to 2 and numbers 5 to 20 ). excised and purified using a MinElute gel extraction kit (Qiagen Inc.) and cloned into the pGEM-T easy vector (Promega Corp., Madison, WI). Considering potential PCR error from Taq DNA polymerase, five recombinant clones were selected averagely from each PCR fragment for DNA sequencing. Genomic DNA sequence was used to search for the cDNA sequence of the gene in an expressed sequence tag (EST) data set randomly sequenced from western white pine cDNA library (unpublished data).

Nucleotide sequences of genomic DNA inserts were determined on both strands on an ABI310 DNA sequencer (Applied Biosystems, Foster City, CA) using a Thermo-cycle sequence kit (Amersham, Baie d'Urfe, QC, Canada). Nucleotide sequence data were compiled and analyzed using Sequencher software (Gene Codes Co,. Ann Arbor, MI). Gene identities were determined by ExPASy Proteomics tools (Swiss Institute of Bioinformatics) and BLAST programs (the National Center for Biotechnology Information) (1).

Genotyping of PmCh4B alleles by genomic PCR. To verify marker-trait associations resulting from SNP data analysis, 265 trees from 18 seed families (numbers 1 to 2 and numbers 5 to 20) were used for direct PCR genotyping of the PmCh4B alleles. Phenotypic data was available for each of the 265 seedlings for levels of quantitative resistance to $C$. ribicola using the above inoculation assessment criteria (Table 1). Based on nucleotide variations of the $P m C h 4 B$ genomic sequences, two $P m C h 4 B$ specific primers were designed for genotyping alleles with an indel of $74 \mathrm{bp}$ in the second intron: forward primer $\mathrm{Ch} 4 \mathrm{Bf}\left(5^{\prime}-\right.$ GTC AAA CTA CTG TCA GAG TTC GA-3') and reverse primer Ch4Br (5'-CCA CCT TCT CTG GAT TAT TCA AC-3'). PCR was performed as described above with some exceptions: an initial template denaturation step at $94^{\circ} \mathrm{C}$ for $3 \mathrm{~min}$; followed by 35 cycles of denaturation at $94^{\circ} \mathrm{C}$ for $40 \mathrm{~s}$, primer annealing at $62^{\circ} \mathrm{C}$ for $1 \mathrm{~min}$, and primer extension at $72^{\circ} \mathrm{C}$ for $1 \mathrm{~min}$; with a final 10 -min extension at $72^{\circ} \mathrm{C}$. The PCR fragments were resolved by $1.5 \%$ agarose gel electrophoresis. According to PCR fragment sizes, the $P m C h 4 B$ genotype of each seedling was determined with one of three expected genotypes: L/L (single band, $318 \mathrm{bp}$ ), L/S (double bands, 318 and $244 \mathrm{bp}$ ), and S/S (single band, $244 \mathrm{bp}$ ).

Genetic data analysis. The program DNASP5.0 (23) was used for genetic diversity analysis. To exclude possible PCR errors, SNPs and indels at a frequency of $>1$ or $5 \%$ were considered for further analysis. Conserved $\mathrm{PmCh} 4 \mathrm{~B}$ haplotypes with a frequency of $>5 \%$ were identified in populations and used for further analysis. The number of polymorphic sites $(S)$ and haplotype diversity $(H d)$ were calculated for the gene locus. Nucleotide diversity was estimated as Watterson's estimator of $\theta\left(\theta_{w}\right)$ from $S(43)$ and as $\pi$, the average number of nucleotide differences per site among sequences in a sample (30). A statistical test of the standard neutral evolution model was performed using both Tajima's $D$ statistic (40) based on differences between $\pi$ and $\theta_{w}$ and $F_{S}$ statistic (11) based on the haplotype frequency distribution.

LD values $\left(r^{2}\right)$ between SNP sites of the same gene were calculated using the trait analysis by association, evolution and linkage (TASSEL) software package, version 2.01 (3), and the DNASP 5.0 program. For multiple SNPs, a weighted average of $r^{2}$

TABLE 2. Pinus monticola open-pollinated seed families and trees for single-nucleotide polymorphism discovery

\begin{tabular}{|c|c|c|c|c|c|c|}
\hline Seed family ID & Trees $(n)$ & Chitinase clones $(n)$ & Phenotype $^{\mathrm{a}}$ & Geographical origin & Latitude, longitude & Altitude (feet) \\
\hline 1. BL3110 & 6 & 31 & SCG & Buttle Lake, BC & $49.71,-125.59$ & 750 \\
\hline 2. Wh3115 & 9 & 46 & Sus & Whistler, BC & $50.13,-122.94$ & 1,220 \\
\hline 3. WK3671 & 13 & 56 & nil & West Kootenay, BC & $50.06,-118.01$ & 1,190 \\
\hline 4. WK3674 & 12 & 48 & nil & West Kootenay, BC & $50.02,-117.05$ & 4,500 \\
\hline 5. $\mathrm{Cv} 05-052$ & 16 & 77 & BR & Colville, WA & $48.64,-117.63$ & 4,000 \\
\hline 6. BS82-413 & 29 & 113 & BR & Mt. Baker-Snoqualmie, WA & $48.68,-121.75$ & 1,700 \\
\hline 7. BS81-003 & 30 & 118 & "X" & Mt. Baker-Snoqualmie, WA & $48.73,-121.66$ & 800 \\
\hline Total & 115 & 483 & $\ldots$ & $\ldots$ & $\ldots$ & $\ldots$ \\
\hline
\end{tabular}

a $\mathrm{SCG}=$ slow canker growth, Sus = susceptible, nil = none, and BR = bark reaction. 
was calculated between each SNP pair (10). $P$ values were determined by permutations based on calculations for the proportion of permuted gamete distribution that were less probable than the observed gamete distribution under the null hypothesis of independence, and the Bonferroni correction was performed to avoid spurious rejections of the null hypothesis in multiple tests (44). Genetic structures of open-pollinated seed families were assessed using an analysis of molecular variance (AMOVA) by calculating $F_{S T}$ (45) with haplotype frequency and their significance was tested to determine the probability of a random $F_{S T}$ with a value the same as or different from the observed one using a permutation-based method using the ARLEQUIN 3.11 program (9). The tests of associations between molecular polymorphism (individual SNP and indel sites, and gene haplotypes) and quantitative resistance phenotype were computed using a mixed linear model (MLM) $(y=$ marker $+\mathrm{Q}+\mathrm{K}+e)$, with accounting the percentages of admixture of each accession ( $Q$ matrix) as cofactors of seed family structure in the software TASSEL (3). With 19 pairs of simple-sequence repeat (SSR) primers developed in eastern white pine (7), a set of SSR markers was developed and each allele of the SSR markers was scored as present or absent (score 1 or 0 ) in the individual tree. SSR marker data were used for the calculation of both $\mathrm{K}$ and $\mathrm{Q}$ matrixes as population structure following the user manual of TASSEL (3). Principal components were used to capture major population subdivisions as Q matrix. Kinship was used to capture more subtle relationships as K matrix.

\section{RESULTS}

PmCh4B characterization. $P m C h 4$ genomic DNA fragments were amplified and cloned by PCR using a pair of primers targeting conserved motifs of class IV chitinases. One DNA fragment with the expected size of $\approx 0.8 \mathrm{~kb}$ was revealed in each seedling. We obtained sequence data from $>500$ recombinant clones, and 483 of them were identified as class IV chitinase gene sequences by BLAST search. The majority of chitinase clones (349 of 483 clones) showed almost identical nucleotide sequences and represented a novel gene (designated as $P m C h 4 B$ ) for the western white pine class IV chitinase family. Based on the genomic DNA sequence, the full-length cDNA sequence of $P m C h 4 B$ was found in an EST data set randomly sequenced from a $P$. monticola cDNA library. PmCh4B displayed only $68 \%$ nucleotide identity and $80 \%$ amino acid identity to $P m C h 4 A$ reported previously in western white pine (25). A BLASTP search in GenBank found that the putative PmCh4B protein also shared high identity with those class IV chitinases from other conifers; $90 \%$ with PsCh4 (ABK22417) in Picea sitchensis, 88\% with Ch4-2 (ACP43363) from Pseudotsuga menziesii, and 86\% with Chia4 (AAQ17048) from Picea abies. Compared with cDNA sequences, both $P m C h 4 A$ and $P m C h 4 B$ genes have the same genomic structure based on gene intron number, position, and phase. These data indicate that $P m C h 4 B$ is a class IV chitinase gene from western white pine.

Nucleotide variations of the $P m C h 4 B$ gene. Because three $P m C h 4 B$ clones were averagely sequenced from each of 115 trees of seven open-pollinated families following PCR amplification
(Table 2), this gene was subjected to a further analysis of genomic variation. In total, $\approx 280-\mathrm{kb} P m C h 4 B$ genomic DNA fragments were sequenced in 115 trees. The total $P m C h 4 B$ aligned region, including indels, covered partial exon1, intron1, exon2, intron2, and partial exon3 with a length of 756 to $839 \mathrm{bp}$, averaging $815 \mathrm{bp}$. The exons of $\mathrm{PmCh} 4 \mathrm{~B}$ had identical lengths with a total coding region of $420 \mathrm{bp}$ but sizes of introns varied greatly, from 336 to $419 \mathrm{bp}$, because of the presence of indels in the intron regions (Table 3 ).

In total, 53 SNPs and 3 indels were identified in the $P m C h 4 B$ gene with at least $1 \%$ minor frequency. PmCh4B showed high haplotype diversity $(H d=0.94)$ (Table 3$)$. For nucleotide diversities in all sequences, estimates were calculated for $\mathrm{PmCh} 4 \mathrm{~B}$ $\left(\pi=0.00965, \theta_{w}=0.01121\right)$. There is a threefold greater variation in polymorphisms at silent sites than at nonsynonymous sites (Table 3).

Tests of both Tajima's $D$ and Fu's $F_{S}$ test statistics were performed to determine significant departures from the null hypotheses of neutral evolution. The negative values for Fu's $F_{S}$ and significant deviations from zero (at least $P<0.001$ ) indicate that $P m C h 4 B$ exhibited a larger number of rare frequency haplotypes than expected (Table 3 ).

LD. In total, 2,213 pairwise LDs were estimated among pairs of SNP sites within 483 genomic sequences of the Pinus monticola chitinase $(\mathrm{PmCh} 4)$ genes. A Fisher's exact test revealed that $\approx 90 \%$ of them were not significant because some PmCh4 sequences were available only from a limited number of seedlings. LD estimates $\left(r^{2}\right)$ with significance were selected and plotted versus distance (bp) within the PmCh4 genomic regions. LD decayed $\approx 40 \%$ over a short distance across all sequences by an $r^{2}$ decrease of $\approx 0.5$ to 0.3 within $\approx 700$ bp (Fig. 2).

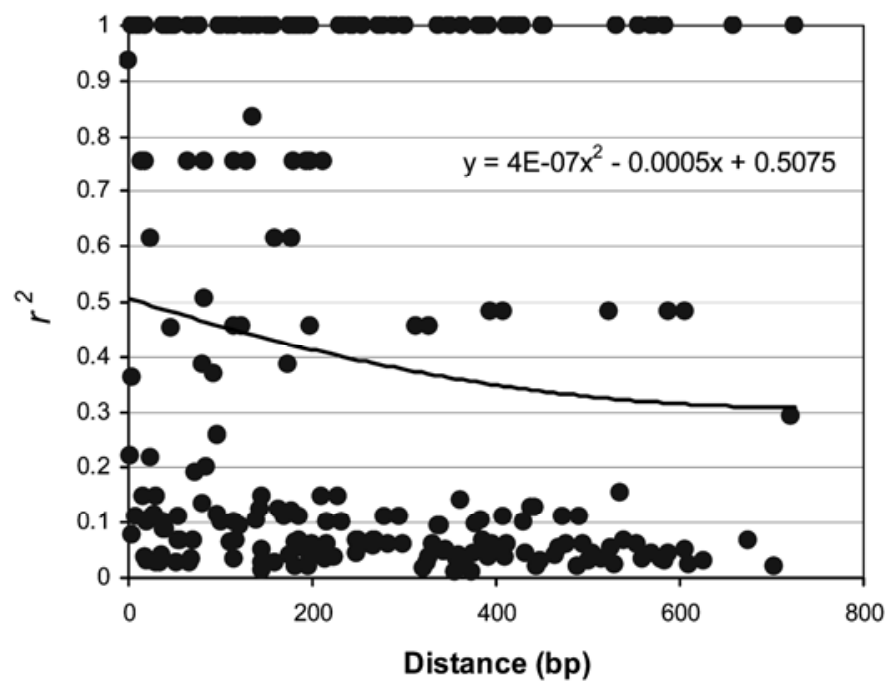

Fig. 2. Scatter plot of the squared correlation of allele frequency $\left(r^{2}\right)$ versus distance in nucleotide base pairs between polymorphic sites of chitinase genes. In total, 483 genomic DNA sequences were analyzed in 115 western white pine trees of seven seed families. Decline in linkage disequilibrium is shown by a second-order polynomial best-fit curve $\left(y=4 \mathrm{E}-07 x^{2}-0.0005 x+\right.$ $0.5075)$.

TABLE 3. Nucleotide polymorphisms and neutrality test of the $P m C h 4 B$ gene

\begin{tabular}{|c|c|c|c|c|c|c|c|}
\hline & $\mathrm{SNP}^{\mathrm{a}}$ & Indel $^{\mathrm{b}}$ & $\pi$ & $\theta_{w}{ }^{\mathrm{c}}$ & $H d(\mathrm{Std})$ & Fu's $F_{S}{ }^{d}$ & Tajima's D \\
\hline Total region & 53 & 3 & 9.65 & 11.21 & $0.94(0.01)$ & $-30.979 * * *$ & -0.401 \\
\hline Nonsynonymous & 21 & 0 & 4.05 & 10.23 & $\ldots$ & $\ldots$ & $\ldots$ \\
\hline Synonymous & 32 & 3 & 13.96 & 11.96 & $\ldots$ & $\ldots$ & $\ldots$ \\
\hline
\end{tabular}

a Single-nucleotide polymorphism.

$\mathrm{b}$ All indels were present in the introns.

c Nucleotide diversity estimates $\left(\pi\right.$ and $\left.\theta_{w}\right)$ are $\times 10^{3}$.

d Significant neutral test at $* * * P<0.001$. 
PmCh4B was revealed to contain 19 common SNP sites and two indel sites with at least $5 \%$ minor allele frequency. The PmCh4B intragenic average $r^{2}$ over all 21 pairwise estimates was 0.13 . Out of 231 tests, $74.9 \%$ of them were significant $(P<0.01)$ based on a weighted average of $r^{2}$ value (Fig. 3). The average $r^{2}$ over 19 SNP pairwise estimates was 0.18 , and $56.6 \%$ of the 171 tests were highly significant with the Bonferroni correction $(P<0.001)$.

Differentiation of $\mathrm{PmCh} 4 \mathrm{~B}$ haplotype among $P$. monticola seed families. The seed families showed considerable variation in phenotypic resistance to WPBR in breeding programs. $F_{S T}$ index is a common pairwise measurement of population genetic differentiation and we used it to reveal genetic structure based on $P m C h 4 B$ haplotype frequency. Six $\operatorname{PmCh} 4 B$ ( $a$ to $f$ ) haplotypes were identified with at least $5 \%$ frequency in the populations. An AMOVA demonstrated that there was a low but significant seed family subdivision within 115 trees of seven seed families (numbers 1 to 7$)\left(F_{S T}=0.163, P<0.001\right)$, indicating that most of the genetic variation $(83.7 \%)$ occurred within the seed families whereas only $16.3 \%$ of the total variance was attributable to diversity among seed families. There was little and a nonsignificant amount of genetic diversity $(0.27 \%, P=0.348)$ between coastal (numbers 1, 2, 6, and 7) and interior (numbers 3 to 5) subgroups. According to the $F_{S T}$ estimates of a pairwise comparison of seven seed families (Table 4), genetic differentiation varied from $0.79 \%$ (between BL3110 and BS82-413) to 39.49\% (between WK3671 and WK3674). These observed genetic differentiations were significant $\left(0.0912<F_{S T}<0.3949, P<0.001\right)$ among most seed

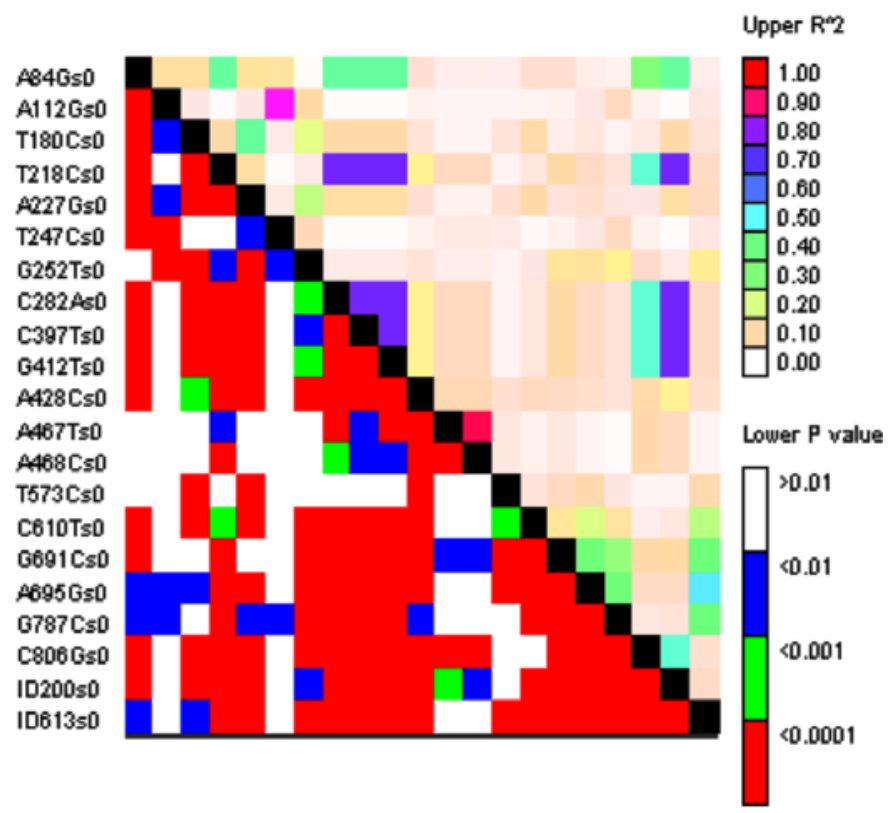

Fig. 3. Plot of intralocus linkage disequilibrium (LD) between 21 polymorphic DNA sites in the PmCh4B region estimated using software package TASSEL. Graphic LD estimates $\left(r^{2}\right)$ were presented in the upper right and $P$ values were indicated in the lower left. families, except pairwise comparisons of family BL3110 with three other families: Wh3115, WK3674, and BS82-413, respectively $\left(0.0079<F_{S T}<0.0767,0.07<P<0.37\right)$.

Association of $\mathrm{PmCh} 4 \mathrm{~B}$ variants to quantitative resistance to $C$. ribicola. Quantitative resistance levels for each tree from 18 seed families were variable from rust dead to stem symptom-free (Table 1). PmCh4B SNP and haplotype data were collected from 115 trees of seven seed families (numbers 1 to 7 ) for association analysis. Of the 21 total SNPs and indels, 10 of them (including 8 SNPs and 2 indels) were significantly associated with quantitative resistance levels $(P<0.05)$ as analyzed using five seed families with available phenotypic data (Table 2). $P m C h 4 B$ genetic variants could explain 5.58\% (SNP A695G, $P<0.05$ ) to $9.13 \%$ (Indel200 and four SNPs: T218C, C282A, C397T, and G412T; $P<0.01)$ of total phenotypic variation as related to partial resistance to $C$. ribicola in the white pine families (Table 5). Among 21 SNPs, only 1 SNP (G787C) resulted in amino acid change (Gly to Ala) but it made no significant contribution to phenotypic variation $(P=0.15)$.

Quantitative resistance levels for tree groups with each of six $P m C h 4 B$ haplotypes ( $a$ to $f$ ) are shown in Figure 4A. Haplotypes $d$ and $f$ (with population frequencies of 8 and 7\%, respectively) had high partial resistance levels, whereas haplotypes $a, b, c$, and $e$ (with population frequencies of $18,20,11$, and $7 \%$, respectively) showed resistance levels in the low to medium ranges. On average, partial resistance levels of trees with $P m C h 4 B-d$ and $P m C h 4 B-f$ were significantly higher than those with $P m C h 4 B-a$ and $P m C h 4 B-b$ (Tukey's highly significant difference [HSD] test, $P<0.05)$. Trees with $P m C h 4 B-c$ and $P m C h 4 B-e$ exhibited medium levels of partial resistance, with no significant difference from trees of the four haplotypes ( $a, b, d$, and $f$ ) (Fig. 4A).

To verify the significant contribution of $P m C h 4 B$ variants to quantitative resistance, the indel613 was transferred into a genespecific PCR marker because it spans an insertion/deletion of 74 bp. PCR genotyping revealed three expected genotypes: L/L (single band, $318 \mathrm{bp}$ ), L/S (double bands, 318 and $244 \mathrm{bp}$ ), and $\mathrm{S} / \mathrm{S}$ (single band, $244 \mathrm{bp}$ ), with population frequencies of 76,18 , and 6\%, respectively. Association of this PmCh4B PCR marker with quantitative resistance levels in a total of 265 trees from 18 seed families (numbers 1 to 2 and numbers 5 to 20) was highly significant $\left(R^{2}=0.051, P<0.0001\right)$ (Table 5). The mean partial resistance level of the tree group with genotype L/S was significantly higher than that with genotype L/L (Tukey's HSD test, $P<$ $0.05)$. However, the $S / S$ group showed no significant difference from either the L/L or L/S group (Fig. 4B).

\section{DISCUSSION}

The diversity pattern of nucleotide sequences varies widely among genes encoding defense- or resistance-related proteins for plants to protect themselves against attacks from pathogens and pests. Relatively high levels of nucleotide polymorphism have been observed in a few genes in Pinus spp. $(4,12,35)$. Despite the fact that plant chitinase genes play an important role in host defense (31), thus far, genetic diversity of chitinase genes has only been investigated in two angiosperms $(17,41)$. In this study,

TABLE 4. $F_{S T}$ statistic for Pinus monticola open-pollinated seed families based on PmCh4B sequences ${ }^{\mathrm{a}}$

\begin{tabular}{|c|c|c|c|c|c|c|c|}
\hline & BL3110 & Wh3115 & WK3171 & WK3174 & Cv05-052 & BS82-413 & BS81-003 \\
\hline BL3110 & & $\ldots$ & $\ldots$ & $\ldots$ & $\ldots$ & $\ldots$ & $\ldots$ \\
\hline Wh3115 & 0.06261 & $\ldots$ & $\ldots$ & $\ldots$ & $\ldots$ & $\ldots$ & $\ldots$ \\
\hline WK3671 & $0.33494 * * *$ & $0.14010^{*}$ & $\ldots$ & $\ldots$ & $\ldots$ & $\ldots$ & $\ldots$ \\
\hline WK3674 & 0.07667 & $0.13377 * *$ & $0.39487 * * *$ & $\ldots$ & $\ldots$ & $\ldots$ & $\ldots$ \\
\hline Cv05-052 & $0.15558 * * *$ & $0.13435 * * *$ & $0.17890 * * *$ & 0.26217 **** & $\ldots$ & $\ldots$ & $\ldots$ \\
\hline BS82-413 & 0.00793 & $0.12710 * * *$ & $0.26355 * * *$ & $0.15285 * * *$ & $0.14547 * * *$ & $\ldots$ & $\ldots$ \\
\hline BS81-003 & $0.09124 * * *$ & $0.15472 * * *$ & $0.23877 * * *$ & $0.22546^{* * * *}$ & $0.13384 * * *$ & $0.09632 * * *$ & $\ldots$ \\
\hline
\end{tabular}

a Significant $F_{S T}$ values: *,**, and $* * *$ indicate $P<0.05,0.01$, and 0.001 , respectively. 
we found that PmCh4B had nucleotide diversity $(\pi=0.00965)$ (Table 3) in a range similar to that of Arabidopsis chitinase genes (AtChiA and AtChiB) (17) and other environmental stress-related genes from loblolly pine (12), Scots pine (42), and Douglas-fir (21). The nucleotide diversity estimates showed variability in conifer species, but not higher than reported in angiosperms (35).

High levels of haploid diversity $(H d=0.94)$ of the PmCh4B gene in white pine seed families were comparable with most chitinase genes in Zea spp. (41). High haplotype diversity was also revealed at the pall locus in P. sylvestris (6) and other conifer loci $(12,42)$. Similar to PmCh4B, other chitinase genes from Arabidopsis and Zea spp. also showed neutral selection as estimated by Tajima's $D$ test $(17,41)$. However, $P m C h 4 B$ was found to have significantly negative Fu's $F_{S}$ test values, indicating a greater number of rare haplotypes than expected. A potential selection sweep was detected at the drought-related $\operatorname{erd} 3$ gene in $P$. taeda (12); genes for dehydrin1 and peroxidase in $P$. densata (27), cold-related dhn4, ef, abaR, and gstl genes in P. sylvestris (42); as well as a water-deficit induced $F 3 H 1$ gene in Douglas-fir (21); however, further evidence is required for a conclusion on the evolutionary selection of these conifer candidate genes related to environmental stresses (12). P. monticola seed families show a wide range of phenotypic variation in genetic resistance to WPBR (20). Our analysis of molecular data confirmed this diversity among seed families used in breeding programs by SNP characterization of the PmCh4B gene.

Pinus is considered to be one of the most genetically variable plant genera. Highly outcrossed species are expected to house heterozygosity levels relatively higher than self-pollinated species and demonstrate little among-population differentiation. P. monticola shows low levels of interpopulation variation but high intrapopulation variation based on analyses of morphological traits, chemicals and isozymes, and DNA markers of various types (amplified fragment length polymorphism [AFLP], random amplified polymorphic DNA [RAPD], and SSR) (2,18,28,39). Our study, based on $P m C h 4 B$ haplotype frequency, also revealed a similar pattern for white pine population structure. $P$. monticola genetic structure has been affected by glaciation during the late Pleistocene (39) and the introduction of the exotic pathogen $C$. ribicola since early 1900 s (18). Significant negative $F_{S}$ in the $P m C h 4 B$ gene is a potential indicator of selective pressures or historic expansion in $P$. monticola populations. As glaciers retreated northward, $P$. monticola invaded and adapted in new environments in mountain regions of western North America from a few southern refugia. During this process, any adaptive selection would have led to western white pine populations in different geographical regions with differential genetic components. Heavy mortality in many natural populations by $C$. ribicola as well as the geographical topology of the sampling regions may have led to limited gene flow between the remaining white pine stands in the past 100 years. All of these factors contribute to genetic differentiation among those seed families grown in isolated geographical sites.
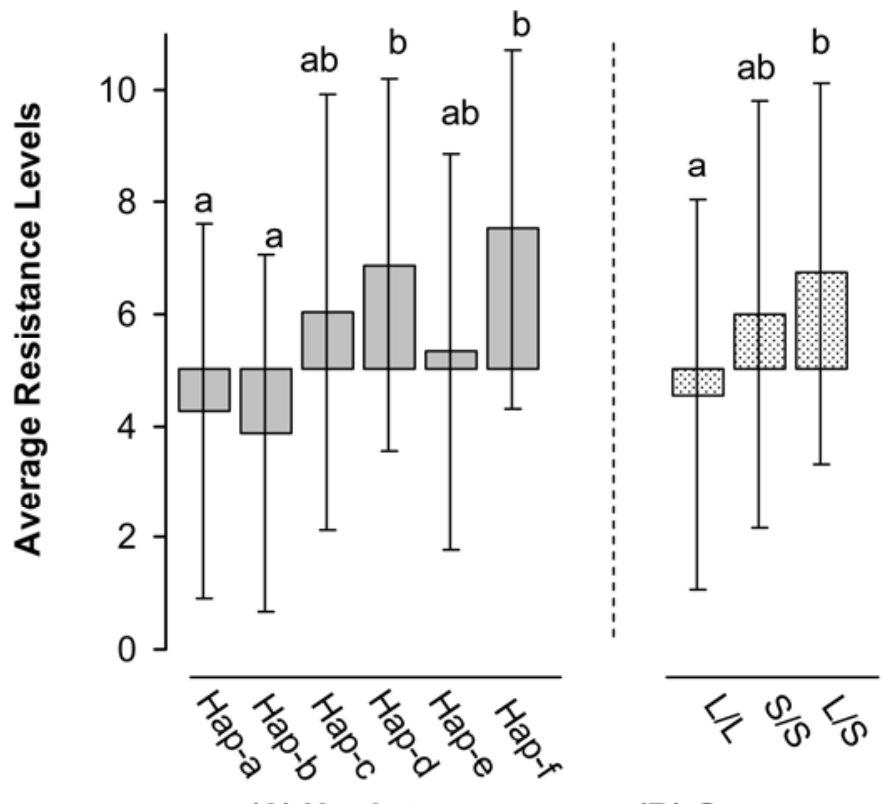

(B) Genotypes

Fig. 4. Association of $P m C h 4 B$ variants with partial resistance levels. A and B, Mean level of partial resistance was shown for major PmCh4B haplotypes (- $a$ to $-f)$, or genotypes (L/L, L/S, and S/S), respectively. Standard deviation (SD) was calculated based on the entire population of each tree group. Statistical difference is significant (Tukey's highly significant difference test, $P<0.05$ ) between groups labeled with different letters ( $a$ and $b$ ).

TABLE 5. Association tests of variants of PmCh4B with quantitative levels of genetic resistance to Cronartium ribicola

\begin{tabular}{|c|c|c|c|c|}
\hline Variation name ${ }^{\mathrm{a}}$ & Location & $P$ marker ${ }^{\mathrm{b}}$ & df error & $R^{2}$ marker \\
\hline A84G & Exon1 & 0.0510 & 85 & 0.0462 \\
\hline $\mathrm{A} 112 \mathrm{G}$ & Exon1 & 0.1134 & 86 & 0.0197 \\
\hline $\mathrm{T} 180 \mathrm{C}$ & Exon1 & 0.9620 & 85 & 0.0001 \\
\hline T218C & Intron 1 & $0.0023 * *$ & 85 & 0.0913 \\
\hline A227G & Intron 1 & 0.9003 & 85 & 0.0017 \\
\hline $\mathrm{T} 247 \mathrm{C}$ & Intron 1 & 0.0580 & 86 & 0.0281 \\
\hline $\mathrm{G} 252 \mathrm{~T}$ & Intron 1 & 0.2233 & 85 & 0.0237 \\
\hline C282A & Intron 1 & $0.0023 * *$ & 85 & 0.0913 \\
\hline C397T & Intron 1 & $0.0023 * *$ & 85 & 0.0913 \\
\hline G412T & Intron 1 & $0.0023 * *$ & 85 & 0.0913 \\
\hline A428C & Intron 1 & $0.0048 * *$ & 85 & 0.0805 \\
\hline A467T & Exon2 & 0.0775 & 85 & 0.0399 \\
\hline A468C & Exon2 & 0.0775 & 85 & 0.0399 \\
\hline T573C & Intron2 & 0.0803 & 85 & 0.0391 \\
\hline C610T & Intron2 & 0.8730 & 85 & 0.0022 \\
\hline G691C & Intron 2 & $0.0222 *$ & 85 & 0.0585 \\
\hline A695G & Intron2 & $0.0266 *$ & 85 & 0.0558 \\
\hline G787C & Exon3 & 0.1545 & 85 & 0.0294 \\
\hline C806G & Exon3 & $0.0072 * *$ & 85 & 0.0748 \\
\hline Indel200 & Intron 1 & $0.0023 * *$ & 85 & 0.0913 \\
\hline Indel613 & Intron2 & $0.0163^{*}$ & 85 & 0.0631 \\
\hline $\mathrm{L} / \mathrm{S}$ & Intron2 & $0.00008 * * *$ & 255 & 0.0513 \\
\hline
\end{tabular}

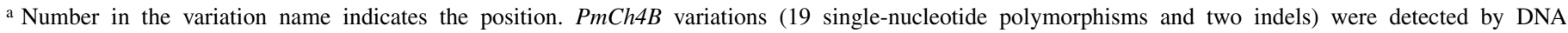
sequencing in seven families, and the alleles (L/S) were detected by polymerase chain reaction directly in 18 seed families.

b Significant differences in bold numbers: *, **, and *** indicate $P<0.05,0.01$, and 0.001 , respectively. 
The seed families used in the current study exhibited highly variable levels of quantitative stem resistance to $C$. ribicola based on their survival rates 4.5 years after inoculation; for example, 88.2\% for BS81-003, 38.5\% for Cv05-052, and 27.1\% for BS82413. At the molecular level, $P$. monticola showed high $F_{S T}$ among seed families (average 0.163) as measured by $P m C h 4 B$ haplotypes. This result is higher than those measured in western white pine Idaho populations by $\operatorname{AFLP}\left(G_{S T}=0.094\right)(18)$ and BC populations by ISSR $\left(F_{S T}=0.057\right)(28)$. The level of structural differentiation revealed among conifer populations is affected greatly by the types of molecular markers (such as allozymes, RAPD, restricted fragment length polymorphism, or SNP) used in the investigation (22) and even by the candidate genes selected in SNP genotyping (32). A genetic structure differentiation was found at 14 isozyme loci in Mexican pine ( $P$. rzedowskii) populations with an average $F_{S T}$ of 0.175 (5) and at seven functional gene loci in $P$. densata populations with an average $F_{S T}$ of 0.105 (27). Diversity values detected in this study by molecular data for $P m C h 4 B$ indicated a large amount of genetic variation $(83 \%)$ within each seed family. No PmCh4B haplotype was common among all tested seed families. Each seed family surveyed from PmCh4B SNPs had a specific combination of haplotypes. Inducible expression in response to $C$. ribicola infection, as well as the exclusive presence of a $26-\mathrm{kDa}$ chitinase isozyme in surviving SCG seedlings of the BL3110 family as opposed to its absence in the completely susceptible family Wh3115 (25), suggests a defense role of the class IV chitinases in quantitative resistance against $C$. ribicola.

In recent years, association genetics has been extensively applied to the dissection of complex adaptive traits and to the discovery of the underlying candidate genes in humans and crops. Our association test revealed that about $50 \%$ of $P m C h 4 B$ variants (SNPs and indels) significantly contributed to stem quantitative resistance in the seed families currently applied in the white pine breeding programs (Table 5). A similar result was reported in rice, where five candidate defense response genes (including chitinase and PR1 genes) accounted for 5.5 to $30 \%$ of the diseased leaf area variation and co-localized with resistance QTL identified by interval mapping (24).

LD structure as well as genetic correlation among polymorphic loci determines the dissecting resolution of the association study in sampling populations. Recombination and the time period required for recombination events to occur are the major elements affecting the LD unit pattern. Of 483 genomic sequences, LD decayed $\approx 40 \%$ within a 700 -bp distance of the western white pine chitinase genes (Fig. 2). LD also decayed rapidly in a few other conifers measured thus far; LD usually declines within $\approx 200 \mathrm{bp}$ in Scots pine (42) and $\approx 2,000$ bp in loblolly pine (12), suggesting that candidate gene-based association mapping in these conifers would be especially powerful. In western white pine seed families used in $C$. ribicola-resistance breeding, a low average level of LD $\left(r^{2}=0.136\right)$ was observed over an $\approx 700$-bp $P m C h 4 B$ sequence. The LDs and LD decay of the PmCh4 family revealed in western white pine populations may provide valuable information for candidate gene-based association mapping in a future work.

Candidate gene-based association analysis could reveal what alleles, haplotypes, or SNPs affect quantitative traits directly, without relying on knowing the LDs if genes are chosen as candidates based on their putative functions or other selection criteria. Because chitinase is well known for its function in degradation of fungal cell walls (31), in this study, members of the $\mathrm{PmCh} 4$ family were selected as candidates to investigate their contribution to quantitative resistance to WPBR. SNPs and molecular markers derived from the $\mathrm{PmCh} 4 \mathrm{~B}$ gene will be useful for exploring their biological roles as defense-related genes in quantitative resistance to WPBR. Significant association of $P m C h 4 B$ SNPs with quantitative resistance levels provides a potential to develop a diagnostic tool from candidate-based poly- morphisms for making future selection of trees with polygenic resistance to $C$. ribicola to include in white pine seed orchards. Application of other and more genetic loci related to disease resistance could be more powerful and precise in the investigation of intraspecific genetic variation to reveal a solid association with resistance phenotypic variation. With the increasing availability of inexpensive DNA sequencing, a modern genomics approach for high-throughput SNP discovery through deep resequencing can identify the most important candidate genes that control complex trait adaptation in tree species $(8,29)$. Such an approach in western white pine could theoretically greatly increase the efficiency of breeding programs for genetic resistance to WPBR.

\section{ACKNOWLEDGMENTS}

This research was supported, in part, by the Canadian Forest Service and the CFS-GRDI fund. We thank A. Zamany, P. Rajkumar, G. Ross, M. Girard-Martel, K. Acharya, and L. Baerg for support on genotyping; J. Hill and A. Kegley for support on phenotyping; H. Chen for preparing Figure 1; A. Song for help on statistical data analysis; and S. Magnussen and A. Islam for critical review of the manuscript.

\section{LITERATURE CITED}

1. Altschul, S. F., Madden, T. L., Schaffer, A. A., Zhang, J., Zhang, Z., Miller, W., and Lipman, D. J. 1997. Gapped BLAST and PSI-BLAST: A new generation of protein database search programs. Nucleic Acids Res. 25:3389-3402.

2. Barnes, B. V. 1967. Phenotypic variation associated with elevation in western white nine. For. Sci. 13:357-364.

3. Bradbury, P. J., Zhang, Z., Kroon, D. E., Casstevens, T. M., Ramdoss, Y., and Buckler, E. S. 2007. TASSEL: Software for association mapping of complex traits in diverse samples. Bioinformatics 23:2633-2635.

4. Brown, G. R., Gill, G. P., Kuntz, R. J., Langley, C. H., and Neale, D. B. 2004. Nucleotide diversity and linkage disequilibrium in loblolly pine. Proc. Natl. Acad. Sci. USA 101:15255-15260.

5. Delgado, P., Piñero, D., Chaos, A., Pérez-Nasser, N., and Alvarez-Buylla, R. A. 1999. High population differentiation and genetic variation in the endangered Mexican pine Pinus rzedowskii (Pinaceae). Am. J. Bot. 86:669-676.

6. Dvornyk, V., Sirviö, A., Mikkonen, M., and Savolainen, O. 2002. Low nucleotide diversity at the pall locus in the widely distributed Pinus sylvestris. Mol. Biol. Evol. 19:179-188.

7. Echt, C. S., May-Marquardt, P., Hseih, M., and Zahorchak, R. 1996. Characterization of microsatellite markers in eastern white pine. Genome 39:1102-1108.

8. Eckert, A. J., Pande, B., Ersoz, E. S., Wright, M. H., Rashbrook, V. K., Nicolet, C. M., and Neale, D. B. 2009. High throughput genotyping and mapping of single nucleotide polymorphisms in loblolly pine (Pinus taeda L.). Tree Genet. Genomics 5:225-234.

9. Excoffier, L., Laval, G., and Schneider, S. 2005. Arlequin ver. 3.0: an integrated software package for population genetics data analysis. Evol. Bioinf. Online 1:47-50.

10. Farnir, F., Coppieters, W., Arranz, J. J., Berzi, P., Cambisano, N., Grisart, B., Karim, L., Marcq, F., Moreau, L., Mni, M., Nezer, C., Simon, P., Vanmanshoven, P., Wagenaar, D., and Georges, M. 2000. Extensive genome-wide linkage disequilibrium in cattle. Genome Res. 10:220-227.

11. Fu, Y. X. 1997. Statistical tests of neutrality of mutations against population growth, hitchhiking and background selection. Genetics 14:915-925.

12. Gonzalez-Martinez, S. C., Ersoz, E., Brown, G. R., Wheeler, N. C., and Neale, D. B. 2006. DNA sequence variation and selection of tag singlenucleotide polymorphisms at candidate genes for drought-stress response in Pinus taeda L. Genetics 172:1915-1926.

13. González-Martínez, S. C., Krutovsky, K. V., and Neale, D. B. 2006. Forest-tree population genomics and adaptive evolution. New Phytol. 170:227-238.

14. González-Martínez, S. C., Wheeler, N. C., Ersoz, E., Nelson, C. D., and Neale, D. B. 2007. Association genetics in Pinus taeda L. I. Wood property traits. Genetics 175:399-409.

15. Hunt, R. S. 1997. Relative value of slow-canker growth and bark reaction as resistance responses to white pine blister rust. Can. J. Plant Pathol. 19:352-357.

16. Jermstad, K. D., Sheppard, L. A., Kinloch, B. B., Delfino-Mix, A., Ersoz, E. S., Krutovsky, K. V., and Neale, D. B. 2006. Isolation of a full-length CC-NBS-LRR resistance gene analog candidate from sugar pine showing 
low nucleotide diversity. Tree Genet. Genomics 2:1614-2942.

17. Kawabe, A., and Miyashita, N. T. 1999. DNA variation in the basic chitinase locus $(C h i B)$ region of the wild plant Arabidopsis thaliana. Genetics 153:1445-1453.

18. Kim, M.-S., Brunsfeld, S. J., McDonald, G. I., and Klopfenstein, N. B. 2003. Effect of white pine blister rust (Cronartium ribicola) and rustresistance breeding on genetic variation in western white pine (Pinus monticola). Theor. Appl. Genet. 106:1004-1010.

19. Kinloch, B. B., Sniezko, R. A., Barnes, G. D., and Greathouse, T. E. 1999. A major gene for resistance to white pine blister rust in western white pine from the western cascade range. Phytopathology 89:861-867.

20. Kolpak, S. E., Sniezko, R. A., and Kegley, A. J. 2008. Rust infection and survival of 49 Pinus monticola families at field site six years after planting. Ann. For. Res. 51:67-80.

21. Krutovsky, K. V., and Neale, D. B. 2005. Nucleotide diversity and linkage disequilibrium in cold-hardiness- and wood quality-related candidate genes in Douglas fir. Genetics 171:2029-2041.

22. Latta, R. G., and Mitton, J. B. 1997. A comparison of population differentiation across four classes of gene marker in limber pine (Pinus flexilis James) Genetics 146:1153-1163.

23. Librado, P., and Rozas, J. 2009. DnaSP v5: A software for comprehensive analysis of DNA polymorphism data. Bioinformatics. doi: 10.1093/ bioinformatics/btp 187

24. Liu, B., Zhang, S., Zhu, X., Yang, Q., Wu, S., Mei, M., Mauleon, R., Leach, J., Mew, T., and Leung, H. 2004. Candidate defense genes as predictors of quantitative blast resistance in rice. Mol. Plant-Microbe Interact. 17:1146-1152.

25. Liu, J.-J., Ekramoddoullah, A. K. M., and Zamani, A. 2005. A class IV chitinase is up-regulated upon fungal infection and abiotic stresses and associated with slow-canker-growth resistance to Cronartium ribicola in western white pine (Pinus monticola, Dougl. Ex D. Don). Phytopathology 95:284-291.

26. Liu, J.-J., Hunt, R., and Ekramoddoullah, A. K. M. 2004. Recent insights into genetic resistance of western white pine to white pine blister rust. Recent Res. Dev. Biotechnol. Bioeng. 6:65-76.

27. Ma, X.-F., Szmidt, A. E., and Wang, X.-R. 2006. Genetic structure and evolutionary history of a diploid hybrid pine Pinus densata inferred from the nucleotide variation at seven gene loci. Mol. Biol. Evol. 23:807-816.

28. Mehes, M S., Nkongolo, K. K., and Michael, P. 2009. Assessing genetic diversity and structure of fragmented populations of eastern white pine (Pinus strobus) and western white pine (P. monticola) for conservation management. J. Plant Ecol. 2:143-151.

29. Neale, D. B., and Ingvarsson, P. 2008. Population, quantitative and comparative genomics of adaptation in forest trees. Curr. Opin. Plant Biol. 11:149-155.
30. Nei, M., and Li, W.-H. 1979. Mathematical model for studying genetic variation in terms of restriction endonucleases. Proc. Natl. Acad. Sci. USA 76:5269-5273.

31. Neuhaus, J. M. 1999. Plant chitinases (PR3, PR4, PR8, PR11). Pages 77105 in: Pathogenesis-Related Proteins in Plants. S. K. Datta and S. Muthukrishnan, eds. CRC Press, New York.

32. Pot, D., McMillan, L., Echt, C., Provost, G. L., Garnier-Géré, P., Cato, S., and Plomion, C. 2005. Nucleotide variation in genes involved in wood formation in two pine species. New Phytol. 167:101-112.

33. Rafalski, A. 2002. Applications of single nucleotide polymorphisms in crop genetics. Curr. Opin. Plant Biol. 5:94-100.

34. Ramalingam, J., Vera-Cruz, C. M., Kukreja, K., Chittoor, J. M., Wu, J.-L., Lee, S. W., Baraoidan, M., George, M. L., Cohen, M. B., Hulbert, S. H., Leach, J. E., and Leung, H. 2003. Candidate defense genes from rice, barley, and maize and their association with qualitative and quantitative resistance in rice. Mol. Plant-Microbe Interact. 16:14-24.

35. Savolainen, O., and Pyhäjärvi, T. 2007. Genomic diversity in forest trees. Curr. Opin. Plant Biol. 10:162-167.

36. Sniezko, R. A., and Kegley, A. 2003. Blister rust resistance experiences in Oregon and Washington: Evolving perspectives. Pages 111-117 in: Proc. 50th West. Int. For. Dis. Work Conf. J. Stone and H. Maffei, eds. Powell River, BC, Canada.

37. Sniezko, R. A., Kegley, A. J., and Danchok, R. 2008. White pine blister rust resistance in North America, Asian and European species-results from artificial inoculation trials in Oregon. Ann. For. Res. 51:53-66.

38. Sorkheh, K., Malysheva-Otto, L. V., Wirthensohn, M. G., TarkeshEsfahani, S., and Martínez-Gómez, P. 2008. Linkage disequilibrium, genetic association mapping and gene localization in crop plants. Genet. Mol. Biol. 31:805-814.

39. Steinhoff, R. J., Joyce, D. G., and Fins, L. 1983. Isozyme variation in Pinus monticola. Can. J. For. Res. 13:1122-1131.

40. Tajima, F. 1989. Statistical method for testing the neutral mutation hypothesis by DNA polymorphism. Genetics 123:585-595.

41. Tiffin, P. 2004. Comparative evolutionary histories of chitinase genes in the genus Zea and family Poaceae. Genetics 167:1331-1340.

42. Wachowiak, W., Balk, P. A., and Savolainen, O. 2009. Search for nucleotide diversity patterns of local adaptation in dehydrins and other coldrelated candidate genes in Scots pine (Pinus sylvestris L.). Tree Genet. Genomics 5:117-132.

43. Watterson, G. A. 1975. On the number of segregating sites in genetical models without recombination. Theor. Pop. Biol. 7:256-276.

44. Weir, B. S. 1996. Genetic Data Analysis II. Sinauer Associates, Sunderland, MA.

45. Weir, B. S., and Cockerham, C. C. 1984. Estimating F-statistics for the analysis of population structure. Evolution 38:1358-1370. 